\title{
Development and Validation Method for Simultaneous Analysis of Retinoic Acid, Hydroquinone and Corticosteroid in Cream Formula by High-Performance Liquid Chromatography
}

\author{
Elvi Rahmayuni, Harmita Harmita*, Herman Suryadi \\ Faculty of Pharmacy, Universitas Indonesia, Kampus UI Depok, West Java 16412, Indonesia.
}

\begin{tabular}{|c|c|}
\hline ARTICLE INFO & ABSTRACT \\
\hline $\begin{array}{l}\text { Article history: } \\
\text { Received on: } 08 / 05 / 2018 \\
\text { Accepted on: } 21 / 08 / 2018 \\
\text { Available online: } 30 / 09 / 2018\end{array}$ & $\begin{array}{l}\text { A simple, precise and rapid reverse phase HPLC-PDA method has been developed and validated for the simultaneous } \\
\text { analysis of hydroquinone (HYQ), dexamethasone (DEX), triamcinolone acetonide (TSA), hydrocortisone acetate } \\
\text { (HYA), betamethasone valerate (BEV) and retinoic acid (REA) in the cream dosage form. The mixture of HYQ, } \\
\text { DEX, TSA, HYA, BEV and REA was separated on Waters X Bridge C18 } 5 \mu \mathrm{m} \text { column ( } 4.6 \mathrm{~mm} \times 250 \mathrm{~mm} \text { ). All } \\
\text { separations were performed with a } 2998 \text { Photodiode Array (PDA) detector on } 210-400 \mathrm{~nm} \text { wavelength, } 400 \mathrm{C} \text { at }\end{array}$ \\
\hline $\begin{array}{l}\text { Key words: } \\
\text { Cream, Hydroquinone, } \\
\text { Retinoic acid, } \\
\text { Corticosteroid, Validation, } \\
\text { HPLC. }\end{array}$ & $\begin{array}{l}\text { gradient system. The retention times of HYQ, DEX, TSA, HYA, BEV, and REA were found to be } 3.69 ; 9.13 ; 9.47 \text {; } \\
9.96 ; 14.92 \text { and } 21.20 \text {. The method showed good linearity with correlation coefficient } 0.9990 ; 0.9991 ; 0.9984 ; 0.9991 ; \\
0.9997 \text { and } 0.9991 \text { over the range of } 25-150 \mu \mathrm{g} / \mathrm{ml} \text { for HYQ, DEX, TSA, HYA, BEV and REA, respectively. The } \\
\text { method was mean recoveries in the range of } 99.05 \text { to } 100.96 \% \text { for all analytes. The developed method can be used in } \\
\text { the routine analysis of HYQ, DEX, TSA, HYA, BEV and REA in the cream formula, as well as for qualitative interest } \\
\text { in cosmetic preparations or for quantitative interest in drug preparations. }\end{array}$ \\
\hline
\end{tabular}

\section{INTRODUCTION}

Hydroquinone (1,4-dihydroxybenzene) is the first line agent in medical therapy of hyperpigmentation. It decreases melanocyte pigment production by inhibiting the conversion of DOPA to melanin through inhibition of the enzyme tyrosinase. Other mechanisms include inhibition of DNA and RNA synthesis, degradation of melanosomes, and destruction of melanocytes. Adverse effects may include dermatitis and ochronosis (Laurence et al., 2011; Charlene, 2014).

Retinoic acid is the organic acid derives from vitamin $\mathrm{A}$ and it is also known as all-trans retinoic acid. It is a drug commonly used to treat acne vulgaris. Acne vulgaris is a common dermatologic problem which could be treated with systemic or topical drugs. More importantly, the combination therapy of

\footnotetext{
${ }^{*}$ Corresponding Author

Harmita Harmita, Faculty of Pharmacy, Universitas Indonesia, Kampus UI Depok, West Java 16412, Indonesia.E-mail: igakadeharmita@ gmail.com
}

topical retinoic acid is more beneficial for the treatment of mild to moderate stages of acne vulgaris (Laurence et al., 2011; Deswal et al., 2017).

Corticosteroids are highly effective drugs which are used to treat inflammatory skin conditions such as eczema and psoriasis. Side effects of corticosteroids for long-term use including pustular psoriasis, permanent skin atrophy and systemic effects such as hypertension, contact dermatitis, and diabetes. Depigmentation is a side effect of topical steroids, corticosteroids might be used as whitening agents in the topical medical preparations illegally sold as cosmetics. Their absorption through the skin can cause adrenal suppression or even Cushing's syndrome. Local side effects of topical corticosteroids include spread and worsening of untreated infection; irreversible thinning of the skin, dermatitis, acne, and hypertrichosis (Laurence et al., 2011; Desmedt et al., 2014).

To determine hydroquinone, retinoic acid and corticosteroid as single components or simultaneous, many studies have been reported in literature such as analysis of hydroquinone (ACM INO 03, 2005), analysis of retinoic acid 
(ACM 001, 2005), simultaneous analysis of hydrocortisone acetate, dexamethasone, betamethasone, betamethasone 17 valerate and triamcinolone acetonide (ACM MAL 07, 2005), simultaneous analysis of hydroquinone and retinoic acid (Aung Myo Htet et al., 2016), simultaneous analysis of hydroquinone, retinoic acid and mometasone furoate (Sheliya et al., 2014) and simultaneous analysis of hydroquinone, ethers hydroquinone and corticosteroids (Gimeno et al., 2016). From the literature survey, there is no analysis method developed for the simultaneous analysis of HYQ, DEX, TSA, HYA, BEV, and REA in cream. Based on fact that these six components are required to be tested in cream cosmetic preparations, especially in facial skin lightening creams, this method also can later be used for the determination levels in preparation of drug creams. Thus, this study aimed to develop fast, simple, inexpensive, sensitive and validated a new high-performance liquid chromatography (HPLC) method for determination of HYQ, DEX, TSA, HYA, BEV and REA simultaneously in cream. The proposed method was validated with validation parameters, which are specificity, linearity, limit of detection (LOD) and limit of quantification (LOQ), precision, accuracy and in accordance with USP guidelines (USP 40, 2016), and later used to analyze cream whether as cosmetic preparation or medicinal preparation.

\section{EXPERIMENTAL}

\section{Materials}

The reference standard of HYQ, DEX, TSA, HYA, $\mathrm{BEV}$, and REA were kindly gifted by Indonesia National Agency of Drug and Food Control. The chemical structures in Figure 1. Commercial HYQ, TSA, HYA, BEV and REA topical cream were purchased from local market in Indonesia, methanol grade for liquid chromatography (Merck), acetonitrile grade for liquid chromatography (Merck). Formic acid 98-100\% pro analysis (Merck), double distilled water used in the experiment was WIDA WI UNICAP $1000 \mathrm{ml}$ (Widatra Bhakti, Indonesia). Cream base oil-in-water purchased from PT. Ikapharmindo Putramas Jakarta, Indonesia.

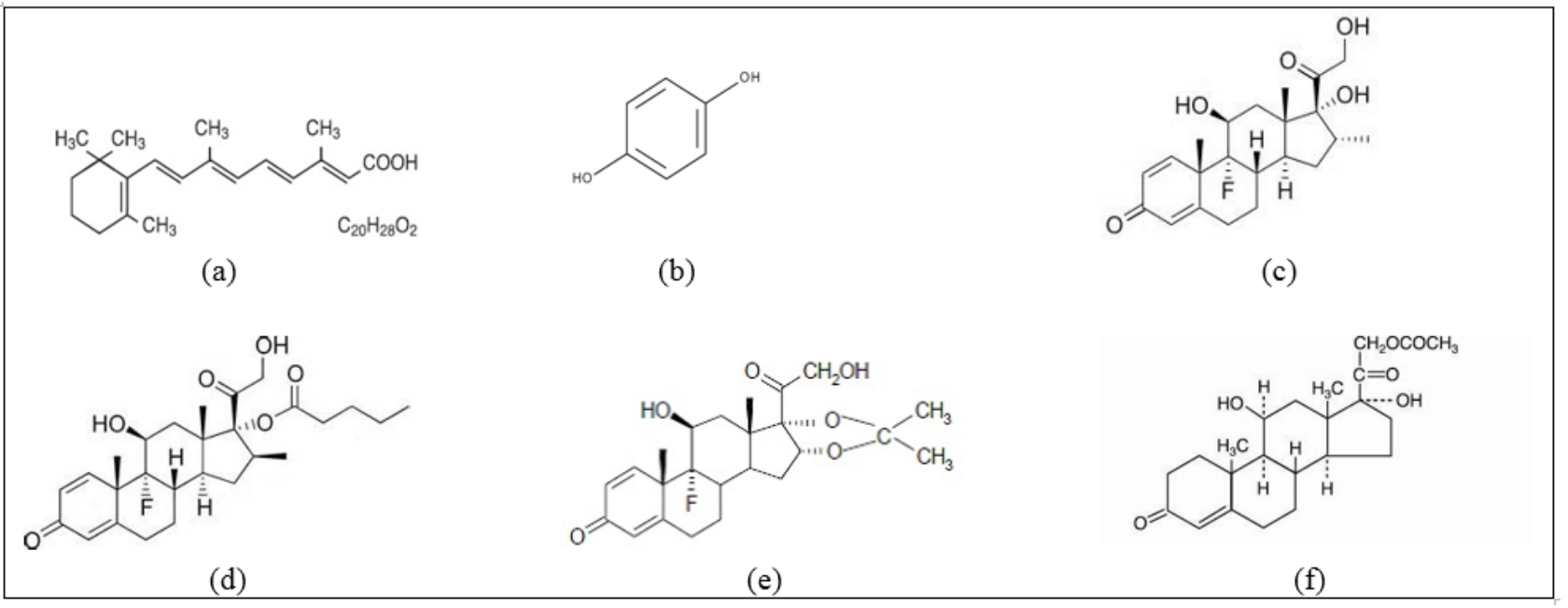

Fig. 1: Chemical structures of (a) Retinoic acid, (b) Hydroquinone, (c) Dexamethasone, (d) Betamethasone valerate, (e) Triamcinolone acetonide, (f) Hydrocortisone acetate.

\section{Instrumentation and chromatographic conditions}

All separations were performed on the HPLC Waters Alliance e2695 with Waters 2998 photo array (PDA) detector. The data were acquired and analyzed using Empower 3 software. Chromatographic separation was carried out on Waters X Bridge C18 $5 \mu \mathrm{m}$ column $(4.6 \mathrm{~mm} \times 250 \mathrm{~mm})$. The component of the mobile phase used for gradient elution was ACN: $0.1 \%$ formic acid solution. Before use, the mobile phase was filtered through $0.45 \mu \mathrm{m}$ membrane filter and degassed by ultrasonication. The flow rate was maintained at $1.2 \mathrm{~mL} /$ min with a column temperature of $40^{\circ} \mathrm{C}$. The injection volume was $20 \mu \mathrm{L}$, and detection was performed at 210-400 nm using a PDA detector.

\section{Preparation of standard stock solutions}

The standard stock solutions of HYQ, DEX, TSA, HYA, $\mathrm{BEV}$, and REA were prepared by accurately weighing $25 \mathrm{mg}$ of each into a $50 \mathrm{ml}$ volumetric flask. The drugs were dissolved in methanol and the solution was diluted to volume. Further dilutions were made from this stock solution become $25,50,75,100,125$ and $150 \mu \mathrm{g} / \mathrm{ml}$.

\section{Preparation of spike stock solutions}

An aliquot $(500 \mathrm{mg})$ of the matrices (cream base oil in water) were weighed into $15 \mathrm{ml}$ tubes and spiked with $5 \mathrm{ml}$ standard stock solution and get 6 concentration of spike solution $25,50,75,100,125,150 \mu \mathrm{g} / \mathrm{ml}$ respectively.

\section{Method validation}

\section{Specificity}

The specificity of this HPLC method was determined by complete separation of HYQ, DEX, TSA, HYA, BEV and REA without any interference of excipients peak with analyte peaks by analyzing the resolution (R), tailing factor (TF) and plate count (PC) parameters of each peak, besides the purity plots from PDA detector. 


\section{Linearity and range}

Determining linearity, calibration curves were plotted over a concentration range of $25-150 \mu \mathrm{g} / \mathrm{mL}$ for HYQ, DEX, TSA, HYA, BEV and REA respectively. A $20 \mu \mathrm{L}$ of sample solution was injected into the chromatographic system. Chromatograms were recorded. All measurements were repeated three times for each concentration and calibration curve was constructed by plotting the peak areas of analyte versus the corresponding drug concentration. Vxo $\leq 5.0$ and R-value $(\geq 0.999)$ confirmed the good linearity of the method.

\section{Limits of detection and quantification}

Using a sample from linearity parameter, the limit of detection (LOD) and limit of quantification (LOQ) were calculated with the formula. The value was calculated from the standard deviation (SD) of response and the slope of the curve $(\mathrm{S})$ by means of the equations: $\mathrm{LOD}=3.3(\mathrm{SD} / \mathrm{S})$ and $\mathrm{LOQ}=10$ $(\mathrm{SD} / \mathrm{S})$, where $\mathrm{SD}$ : standard deviation of the detector response; $\mathrm{S}$ : slope of the calibration curve.

\section{Precision}

The precision of the proposed method was assessed by preparing three different sample solutions at low, medium, and high concentrations, which were freshly prepared and analyzed. The precision $\%$ relative standard deviation (\% RSD) was assessed by analyzing standard drug solutions within the calibration range. The precision of the method was expressed as RSD \% and Horwitz value.

\section{Accuracy}

Accuracy was calculated as the difference between theoretical added amount and the practically achieved amount. To check the degree of accuracy of the method, recovery studies were performed in triplicate by standard addition method at
$50 \%, 100 \%$, and $150 \%$. The known amount of standard HYQ, DEX, TSA, HYA, BEV, and REA were added to pre-analyzed samples and were subjected to the proposed method (Petrova et al., 2013).

\section{Analysis of marketed formulation}

The validated method, used for testing cream samples on the market. The sample used in this test is a drug cream, which is; HYQ $2 \%$, DEX not tested, TSA $0.1 \%$, HYA $1 \%$, BEV $0.1 \%$, and REA $0.1 \%$. A portion of the cream was weighed about $500 \mathrm{mg}$ into the appropriate tube for getting $100 \mu \mathrm{g} / \mathrm{ml}$ concentration. The sample extracted with methanol with the aid of ultrasonication for 15 minutes, then filtered using $0.45 \mu \mathrm{m}$ PTFE filter.

\section{RESULT AND DISCUSSION}

\section{Optimization of procedures}

The HPLC procedure was optimized for simultaneous determination of HYQ, DEX, TSA, HYA, BEV and REA. Good resolution of both components was obtained with the gradient system $0.1 \%$ formic acid in water as solvent $\mathrm{A}$ and Acetonitrile as solvent $\mathrm{B}$. The gradient was, in $0 \mathrm{~min} 8 \% \mathrm{~A}, 5 \mathrm{~min} 8 \% \mathrm{~A}, 16$ min $50 \% \mathrm{~A}, 23 \min 95 \% \mathrm{~A}, 28 \min 8 \% \mathrm{~A}$, and then return to initial condition. The flow rate of $1.2 \mathrm{~mL} /$ minutes was optimum, with oven temperature $40^{\circ} \mathrm{C}$. Using PDA detector the chromatograms was read with Waters Empower 3 Chromatography software by using time wavelength procedure. HYQ were read at $289 \mathrm{~nm}$, corticosteroid DEX, TSA, HYA and BEV were read at $240 \mathrm{~nm}$, and REA was read at $321 \mathrm{~nm}$. The six component already read on their optimum wavelength (Table 1). The system suitability parameters for HPLC chromatogram are as follows (Table 2). The average retention times for HYQ, DEX, TSA, HYA, BEV and REA was found to be $3.693 ; 9.130 ; 9.470 ; 9.964 ; 14.919$ and 21.202 respectively (Figure 2 ).

Table 1: The Final optimized condition for the analysis.

\begin{tabular}{|c|c|c|c|c|}
\hline No & Parameter & & Specification & \\
\hline 1 & Column & $\mathrm{C} 18$ & & \\
\hline 2 & Particle size & $5 \mu \mathrm{m}$ & & \\
\hline \multirow[t]{4}{*}{4} & Wavelength & Time wavelength & & \\
\hline & & Time & Wavelength & \\
\hline & & 0 & 289 & \\
\hline & & 18 & 321 & \\
\hline \multirow[t]{4}{*}{5} & Mobile phase & Gradient & & \\
\hline & & Time & Formic Acid $0.1 \%$ & Acetonitrile \\
\hline & & 0 & 8 & 92 \\
\hline & & 5 & 8 & 92 \\
\hline 6 & Flow rate & $1.2 \mathrm{ml} / \mathrm{min}$ & & \\
\hline 7 & Injection volume & $20 \mu 1$ & & \\
\hline 8 & Column temp & $40^{\circ} \mathrm{C}$ & & \\
\hline
\end{tabular}


Table 2: System suitability parameters.

\begin{tabular}{|c|c|c|c|c|c|c|c|}
\hline System Suitability Parameters & HQ & DM & TA & HA & BV & RA & Limits \\
\hline Retention time & 3.697 & 9.130 & 9.47 & 9.964 & 14.919 & 21.202 & - \\
\hline Resolution & - & 25.3039 & 3.2606 & 4.2133 & 23.3667 & 29.7337 & $>2$ \\
\hline Tailing & 0.807 & 1.248 & 1.352 & 1.222 & 1.273 & 1.229 & $<2$ \\
\hline Plate Count & 1950 & 132392 & 112438 & 99335 & 37808 & 5286214 & $>1000$ \\
\hline
\end{tabular}

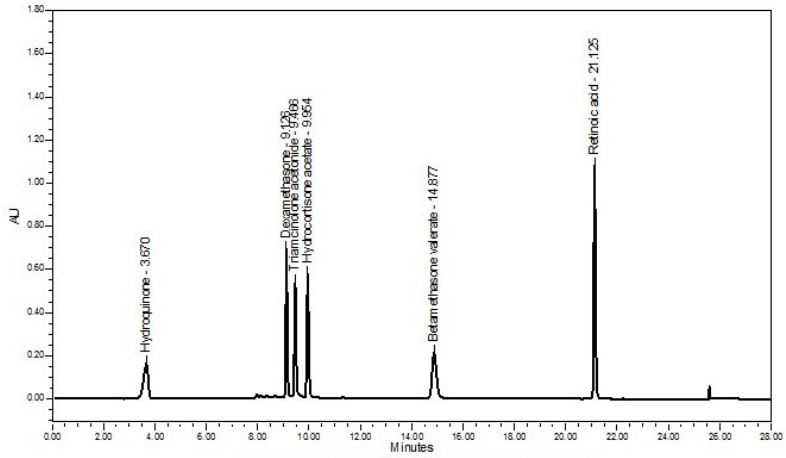

Fig. 2: Chromatogram of hydroquinone, dexamethasone, triamcinolone acetonide, hydrocortisone acetate, betametasone valerate and retinoic acid (reference standard).

\section{Specificity}

This HPLC method was specified, determined by complete separation of HYQ, DEX, TSA, HYA, BEV and REA without any interference of excipients peak with analyte peaks (Figure 2, Figure 3). The resolution (R), tailing factor (TF) and Plate Count (PC) parameters of each peak meet the requirement. It was less than 2 for $\mathrm{TF}$, more than 2 for $\mathrm{R}$ and more than 1000 for PC (Table 2). Beside that the purity plot shows that the six component was pure (Figure 4).

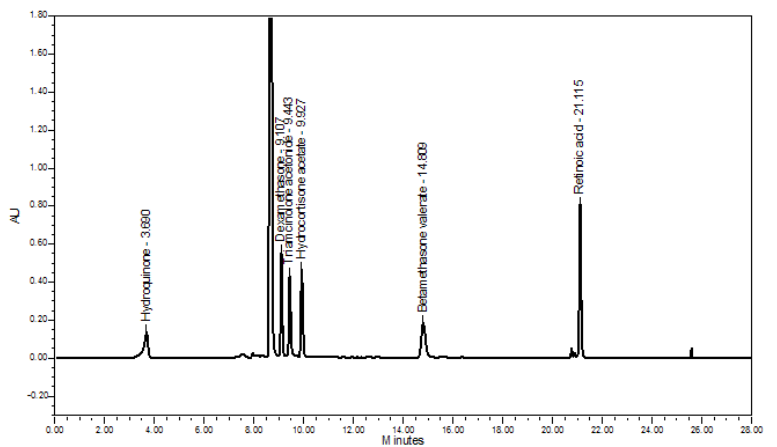

Fig. 3: Chromatogram of hydroquinone, dexamethasone, triamcinolone acetonide, hydrocortisone acetate, betametasone valerate and retinoic acid reference standard in cream bases oil in water.

\section{Linearity and range}

From the calculation were got that Vxo of each component $\leq 5.0$, and $\mathrm{R}$ value $\geq 0.999$ confirmed the good linearity of the method (Table 3 ). Linear regression data for the calibration plots revealed good linear relationships between response and concentration. The linear regression equations were $\mathrm{Y}=17766.04 \mathrm{X}+19823.77(\mathrm{r}=0.9990)$ for $\mathrm{HYQ}, \mathrm{Y}=26943.51 \mathrm{X}$ $+98029.48(\mathrm{r}=0.9991)$ for $\mathrm{DEX}, \mathrm{Y}=23602.22 \mathrm{X}+256560.22(\mathrm{r}$
$=0.9984)$ for TSA, $\mathrm{Y}=28540.38 \mathrm{X}+39937.17(\mathrm{r}=0.9991)$ for HYA, $\mathrm{Y}=21217.47 \mathrm{X}+290070.95(\mathrm{r}=0.9997)$ for $\mathrm{BEV}$, and $\mathrm{Y}=$ $41552.68 X+298920.30(r=0.9991)$ for REA (Table 5).

Table 3: Specificity, Range, LOD and LOQ parameters.

\begin{tabular}{|c|c|c|c|c|c|c|c|c|}
\hline No & Parameter & HQ & DM & TA & HA & BV & $\mathbf{R A}$ & Limits \\
\hline 1 & Specificity & \multicolumn{7}{|c|}{ No interference of excipients peak with analyte peaks } \\
\hline \multirow[t]{5}{*}{2} & Range & & & & & & & \\
\hline & $\begin{array}{l}\text { - Linearity } \\
\text { range }\end{array}$ & \multicolumn{7}{|c|}{$25-150 \mu \mathrm{g} / \mathrm{ml}$} \\
\hline & $\begin{array}{c}\text { - Target } \\
\text { concentration }\end{array}$ & \multicolumn{7}{|c|}{$100 \mu \mathrm{g} / \mathrm{ml}$} \\
\hline & - Vxo & 1.670 & 1.545 & 2.051 & 1.576 & 0.935 & 1.526 & $\leq 5.0$ \\
\hline & $-\mathrm{R}$ & 1.000 & 1.000 & 0.999 & 1.000 & 1.000 & 1.000 & $\geq 0.999$ \\
\hline 3 & LOD & 2.123 & 1.964 & 2.607 & 2.003 & 1.188 & 1.940 & - \\
\hline 4 & LOQ & 7.077 & 6.545 & 8.689 & 6.676 & 3.960 & 6.465 & - \\
\hline
\end{tabular}

Table 4: Regression.

\begin{tabular}{ccc}
\hline Agents & Regression Equation & R2 \\
\hline HYQ & $\mathrm{y}=17918.84 \mathrm{x}+19823.77$ & 0.9990 \\
DEX & $\mathrm{y}=26835.74 \mathrm{x}+98029.49$ & 0.9991 \\
TSA & $\mathrm{y}=23408.69 \mathrm{x}+25656.23$ & 0.9984 \\
HCA & $\mathrm{y}=28243.56 \mathrm{x}-39937.17$ & 0.9991 \\
BMV & $\mathrm{y}=21340.53 \mathrm{x}+290070.95$ & 0.9997 \\
REA & $\mathrm{y}=41785.38 \mathrm{x}-298920.31$ & 0.9991 \\
\hline
\end{tabular}

\section{Limits of detection and quantitation}

The LOD and the LOQ for this simultaneous analysis were found to be $2.14 \mu \mathrm{g} / \mathrm{mL}$ and $7.14 \mu \mathrm{g} / \mathrm{mL}$ for HYQ, 1.96 $\mu \mathrm{g} / \mathrm{mL}$ and $6.52 \mu \mathrm{g} / \mathrm{mL}$ for DEX, $2.59 \mu \mathrm{g} / \mathrm{mL}$ and $8.62 \mu \mathrm{g} / \mathrm{mL}$ for TSA, $1.98 \mu \mathrm{g} / \mathrm{mL}$ and $6.61 \mu \mathrm{g} / \mathrm{mL}$ for HYA, $1.19 \mu \mathrm{g} / \mathrm{mL}$ and $3.98 \mu \mathrm{g} / \mathrm{mL}$ for BEV, and $1.95 \mu \mathrm{g} / \mathrm{mL}$ and $6.50 \mu \mathrm{g} / \mathrm{mL}$ for REA, respectively (Table 3 ).

\section{Precision}

The repeatability of the method was carried out and the high values of the mean assay and low values of \% RSD and the Horrat value for HYQ, DEX, TSA, HYA, BEV and REA revealed the proposed method is precise. The results showed in (Table 5).

\section{Accuracy}

The recovery of the method was $99.05-100.96 \%$. The values of recovery in Table 5 indicate the method is accurate. 

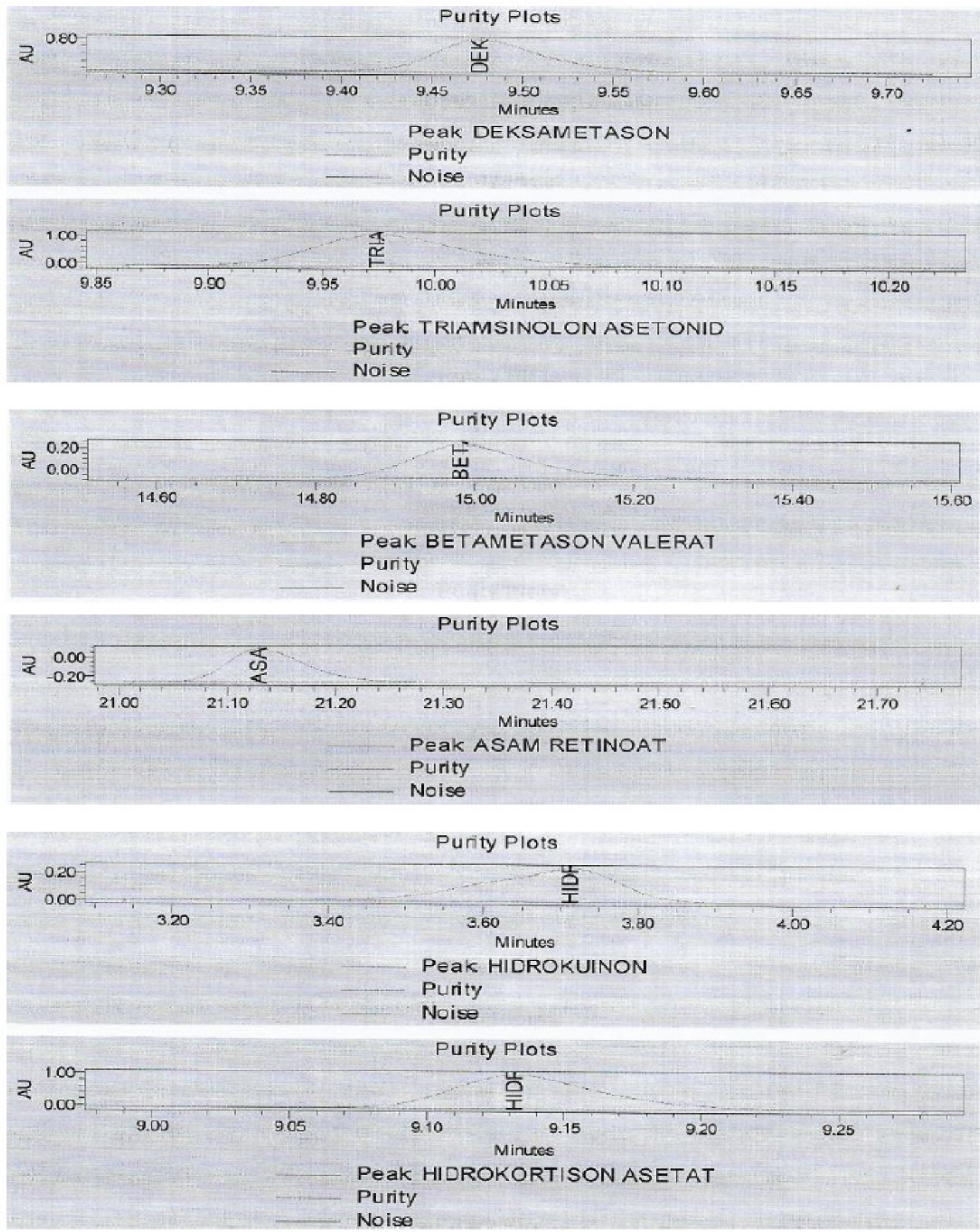

Fig. 4: The purity plots of hydroquinone, dexamethasone, triamcinolone acetonide, hydrocortisone acetate, betametasone valerate and retinoic acid.

\section{Analysis of marketed formulation}

In this market sample analysis, DEX sample was not tested. Analysis was done to commercial HYQ $(2 \%)$, TSA $(0.1 \%)$, HYA $(0.1 \%)$, BEV $(0.1 \%)$, and REA $(0.1 \%)$ cream. Sharp and well-defined peaks for HYQ, TSA, HYA, BEV, and REA were obtained respectively when scanned with PDA detector at 210-400 $\mathrm{nm}$. The result of the measurement is presented in Table 6 .

\section{CONCLUSION}

A simple, linear, accurate and precise HPLC method was 
developed and validated for the simultaneous analysis of HYQ, DEX, TSA, HYA, BEV and REA in the cream topical formulation. The validation results revealed that the methods are precise, linear and accurate, which proves the reliability of the proposed method. The method could be successfully applied for routine analysis and quality control of pharmaceutical dosage forms.

Table 5: Precision and accuracy parameters.

\begin{tabular}{|c|c|c|c|c|}
\hline \multirow{2}{*}{\multicolumn{2}{|c|}{ Concentration }} & \multicolumn{3}{|c|}{ Parameter } \\
\hline & & \multicolumn{2}{|c|}{ Precision } & \multirow{2}{*}{$\begin{array}{c}\text { Accuracy } \\
\% \text { Recovery }\end{array}$} \\
\hline & & RSD (\%) & Horrat & \\
\hline \multirow{3}{*}{ HQ } & 50 & 1.289 & 0.606 & 99.70 \\
\hline & 100 & 0.289 & 0.151 & 100.96 \\
\hline & 150 & 1.656 & 0.918 & 99.28 \\
\hline \multirow{3}{*}{$\mathrm{DM}$} & 50 & 1.331 & 0.626 & 99.76 \\
\hline & 100 & 1.621 & 0.846 & 99.05 \\
\hline & 150 & 0.992 & 0.551 & 100.80 \\
\hline \multirow{3}{*}{ TA } & 50 & 1.417 & 0.667 & 99.79 \\
\hline & 100 & 2.535 & 1.323 & 99.14 \\
\hline & 150 & 1.816 & 1.009 & 100.84 \\
\hline \multirow{3}{*}{ HA } & 50 & 1.187 & 0.559 & 100.07 \\
\hline & 100 & 2.011 & 1.050 & 99.34 \\
\hline & 150 & 1.905 & 1.058 & 100.63 \\
\hline \multirow{3}{*}{$\mathrm{BV}$} & 50 & 1.300 & 0.612 & 100.27 \\
\hline & 100 & 0.932 & 0.486 & 99.28 \\
\hline & 150 & 0.118 & 0.621 & 100.43 \\
\hline \multirow{3}{*}{ RA } & 50 & 0.232 & 0.109 & 99.83 \\
\hline & 100 & 0.912 & 0.476 & 99.27 \\
\hline & 150 & 0.517 & 0.287 & 100.14 \\
\hline
\end{tabular}

Table 6: Result from the assay of marketed formulation.

\begin{tabular}{ccccc}
\hline Sample & Component & \% Mean Amount & SD & \% RSD \\
\hline 1 & Hydroquinone & 99.86 & 0.8600 & 0.8612 \\
2 & Triamcinolone acetonide & 100.13 & 0.3022 & 0.3018 \\
3 & Hydrocortisone acetate & 97.02 & 0.1760 & 0.1814 \\
4 & Betamethasone valerate & 102.50 & 0.7606 & 0.7420 \\
5 & Retinoic acid & 104.87 & 0.9222 & 0.8795 \\
\hline
\end{tabular}

\section{CONFLICT OF INTEREST}

The authors declare no conflicts of interest.

\section{ACKNOWLEDGMENT}

The authors are grateful to the Indonesia National Agency of Drug and Food Control (BPOM RI) for supporting all this research cost. The authors are also thankful to the Faculty of Pharmacy Indonesia University, for encouraging and motivating for this research work.

\section{REFERENCES}

Asean Cosmetic Method. Identification and Determination of Hydroquinone in Cosmetic Products by TLC and HPLC. 2005. ACM INO 03.

Asean Cosmetic Method. Identification of hydrocortisone Acetate, dexamethasone, betamethasone, betamethasone 17 valerate and triamcinolone acetonide in cosmetic products by TLC and HPLC. 2005. ACM MAL 07.

Asean Cosmetic Method. Identification of Retinoic acid (Retinoic Acid) in Cosmetic Products by TLC and HPLC. 2005. ACM 001

Aung Myo Htet, EI Ei Thin, Mi Mi Saw, Soe Win. Chemical analysis of hydroquinone and retinoic acid contents in facial whitening creams. Asian Journal Of Pharmaceutical Sciences II. 2016. pp. 89-90.

Charlene DeHaven. Hydroquinone. www.innovativeskincare. 2014.

Desmedt B, Van Hoeck E, Rogiers V, Courselle P, De Beer JO, De Paepe K, Deconinck E. Characterisation of suspected illegal skin whitening cosmetics. J Pharm Biomed Anal, 2014; 90:85-91.

Deswal A, Dhanda H. Pharmacology, and impact of retinoic acid on the treatment of premalignant squamous lesions of the oral cavity. The Pharma Innovation Journal, 2017; 6(7):20-26.

Gimeno P, Maggio AF, Bancilhon M, Lassu N, Gornes H, Brenier C, Lempereur L. HPLC-UV Method for the identification and screening of Hydroquinone, ethers of hydroquinone and corticosteroids possibly used as skin-whitening agents in Illicit Cosmetic Products. Journal of Chromatographic Science, 2016; 54(3):343-352.

Laurence Brunton, Bruce Chabner, Bjorn Knollman. Goodman $\&$ Gilman's the pharmacological basis of therapeutics (12 ${ }^{\text {th }}$ ed.). New York: McGraw-Hill Companies Inc. 2011.

Petkova N., P. Brabant, An. Masson, P. Denev. 2013. HPLC analysis of mono- and disaccharides in food products, Scientific works of UFT, Volume LX, "Food Science, engineering and technologies", 18-19 October 2013, Plovdiv, 761-765.

Sheliya K., Shah K., Kapupura P. Development and validation of analytical method for simultaneous estimation of mometasone furoate, hydroquinone and retinoic acid in the topical formulation by RP-HPLC. Journal of Chemical and Pharmaceutical Research, 2014; 6(4):934-940.

United States Pharmacopoeia ( $40^{\text {nd }}$ ed.). Rockville: The United States Pharmacopeial Convention. 2016.

How to cite this article:

Rahmayuni E, Harmita H, Suryadi H. Development and Validation Method for Simultaneous Analysis of Retinoic Acid, Hydroquinone and Corticosteroid in Cream Formula by HighPerformance Liquid Chromatography. J App Pharm Sci, 2018; 8(09): 087-092. 